\title{
A Study on Coloring Properties of Rheum emodi on Jute Union Fabrics
}

\author{
Lopamudra Nayak \\ Orissa University of Agriculture \& Technology, Bhubaneswar 751003, India \\ Correspondence should be addressed to Lopamudra Nayak; licha.lopa@gmail.com
}

Received 28 September 2013; Revised 4 December 2013; Accepted 26 December 2013; Published 11 February 2014

Academic Editor: Anindya Ghosh

Copyright (C) 2014 Lopamudra Nayak. This is an open access article distributed under the Creative Commons Attribution License, which permits unrestricted use, distribution, and reproduction in any medium, provided the original work is properly cited.

\begin{abstract}
Jute-cotton and jute-wool union fabrics have been printed with colorant extracted from Rheum emodi with guar gum and albumin as thickening agents and aluminium sulphate, copper sulphate, and ferrous sulphate as mordants. Printing with Rheum emodi colorant with different mordants resulted in different shades ranging from yellowish brown, deep brown, reddish brown, and gray shades to olive black. The $K / S$ value showed that mordants, namely, $\mathrm{CuSO}_{4}$ and $\mathrm{FeSO}_{4}$, exhibited high colour absorption regardless of the nature of material used. All the printed samples have good to excellent wash, rubbing and light fastness properties regardless of the nature of materials, mordants, and thickeners used. Guar gum is closely at par with albumin as a thickening agent and considering the cost and availability of raw material, guar gum is the better choice for the textile industry.
\end{abstract}

\section{Introduction}

Renewable, biodegradable, and sustainable natural fibers and natural colorants could be potential substitutes for energyintensive and petrochemical-based synthetic fibers and colorants in many applications and serve as an effective way of reducing the impact textiles have on the environment. The most classically known fibers such as jute, cotton, and wool are environmentally friendly, healthy, and comfortable. In addition, use of natural colorants on these fibers has become very much popular throughout the world due to its ecofriendliness, and aesthetic approach.

Jute is a lingo-cellulosic composite natural bast fiber; its major constituent components being cellulose, hemicellulose, and lignin. It has high tensile strength with low extensibility, which helps to make the best quality industrial yarn and fabric. The inherent drawback of jute such as harshness, brittleness, and low extensibility pose a hindrance for its use as furnishings and apparels $[1,2]$. To overcome these problems jute fabrics could be produced with blend or union with other natural and manmade fibers. Furthermore, these fabrics are subjected to coloration to improve its appearance.

Though renewable dye resources provide important alternatives for fossil-based colorants, from the sustainability point of view, it is desirable to use natural dyes to a greater extent. Rheum emodi commonly known as Himalayan rhubarb is one such natural colorant found in the subalpine and alpine Himalayas at an altitude of 3000-5000 meters. Rheum emodi is a medicinal herb and belongs to the family Polygonaceae. The Indian rhubarb (Rheum emodi) commonly known as "Dolu" (Sanskrit: Amlaparni, Revatchini; Hindi: Revand chini) are reported to be used for curing of a variety of diseases, its main effect being a positive and balancing effect upon the whole digestive system. The rhizomes and roots of Rheum emodi yield a yellow coloring matter which could be used for textile coloration. The plant contains 3-5\% anthracene derivatives. In the plant the anthraquinoid components are present in reduced form as anthraglycosides, which hydrolyze and oxidize to the respective anthraquinone. The extracted dye contains a complex mixture of anthraquinones; relevant compounds are Emodin, Chrysophanol, Aloeemodin, Rhein, and Physcion and the chief colouring component is chrysophanic acid [36].

The alkaline extract of root gives a brown colored powdered dye. The structures of the molecules are shown in Figure 1.

The formation of complexes due to the presence of metal salt from mordanting considerably improves dye uptake and all round fastness properties. Mordant brings about change 
<smiles>Cc1cc(O)c2c(c1)C(=O)c1cc(O)cc(O)c1C2=O</smiles><smiles>Cc1cc(O)c2c(c1)C(=O)c1cccc(O)c1C2=O</smiles><smiles>O=C1c2cccc(O)c2C(=O)c2c(O)cc(CO)cc21</smiles><smiles>O=C(O)c1cc(O)c2c(c1)C(=O)c1c(O)cccc1C2=O</smiles><smiles>COc1cc(O)c2c(c1)C(=O)c1cc(C)cc(O)c1C2=O</smiles>

FIgURE 1: Some of the anthraquinoid dye structure of Rheum emodi: Emodin, Chrysophanol, Aloeemodin, Rhein, and Physcion. of the hue of the natural colorants, which can be utilized with advantage to produce different shades on protein and cellulosic substrates. Keeping environment related issues and adoption of cleaner technology in view, inorganic salts such as, aluminium sulphate, potash alum, and ferrous sulphate can be employed as mordanting agent in view of their good complex forming ability and environmental safe character. Myrobalan is used as a source of tannin either alone or in combination with inorganic salts as mordanting agents especially for cotton $[5,6]$.

Thickeners are needed to help control the dye, to give it some bulk when printing with the dye. Guar gum can be used for most types of printing as it is very stable in all $\mathrm{pH}$ levels. Guar is a native to the Indian subcontinent and offers a cheaper alternative to Gum Arabic and Gum Senegal. Albumin can be used both as a thickening and a fixing agent in textile printing. They are widely distributed in plant and animal tissues, for example, legumelin of peas, leucosin of wheat, ovalbumin of egg, serum albumin of bovine, and lactalbumin of milk and so forth $[7,8]$.

The present study examines the coloring properties of natural colorant Rheum emodi on jute/cotton and jute/wool union fabrics and compares the performances of albumin and guar gum as thickening agents along with aluminium sulphate, copper sulphate, and ferrous sulphate as mordants.

\section{Materials and Methods}

2.1. Materials. Mill-scoured and bleached jute/cotton $(60: 40)$ union fabric with cotton yarn in the warp and jute/ cotton yarns in the weft direction (plain weave, thickness $1.95 \mathrm{~mm}$, EPI:17; PPI:17) and jute/wool (60:40) union fabric with wool yarn in the warp and jute/wool yarns in the weft direction (plain weave, thickness $1.97 \mathrm{~mm}$, EPI:17; PPI:14) were purchased from the market. Jute yarns used in the fabrics were cream colored (not bleached white).

Natural dye powder, Rheum emodi (alkaline extract; brown colored powder), and myrobalan (Terminalia chebula) were obtained from M/s ALPS Industries Ltd., Ghaziabad, India. Thickeners, namely, guar gum and albumin, and mordants such as alum, copper sulphate $\left(\mathrm{CuSO}_{4}\right)$, ferrous sulphate $\left(\mathrm{FeSO}_{4}\right)$ and all other chemicals such as acetic acid and glycerin used were of laboratory grade.

\subsection{Methods}

2.2.1. Scouring. Jute/cotton and jute/wool union fabrics were washed with nonionic detergent $(2 \mathrm{~g} / \mathrm{L})$ and washing soda
TABLE 1: Quantity of mordant and thickener.

\begin{tabular}{lccc}
\hline Mordant name & $\begin{array}{c}\text { Quantity of } \\
\text { mordant }(\mathrm{gm})\end{array}$ & $\begin{array}{c}\text { Quantity of } \\
\text { thickener }(\mathrm{gm})\end{array}$ & $\begin{array}{c}\text { Total } \\
\text { quantity }(\mathrm{gm})\end{array}$ \\
\hline Alum & 6 & 94 & 100 \\
Copper sulphate & 4 & 96 & 100 \\
Ferrous sulphate & 4 & 96 & 100 \\
\hline
\end{tabular}

$(0.5 \mathrm{~g} / \mathrm{L})$ for half an hour at a temperature of $50^{\circ} \mathrm{C}-60^{\circ} \mathrm{C}$, keeping the material to liquor ratio at $1: 30$ to facilitate subsequent mordanting and printing operation. The scoured material was thoroughly washed with tap water and dried at room temperature.

2.2.2. Treatment with Myrobalan. Half of the fabric samples were treated with myrobalan $(20 \mathrm{~g} / \mathrm{L})$ for 15 minutes at a temperature of $40^{\circ} \mathrm{C}-60^{\circ} \mathrm{C}$, keeping the material to liquor ratio at $1: 20$. The materials were taken out from bath and squeezed evenly and dried. Precaution is to be taken, not to dry the treated cloth in direct sun light as the surface exposed to sun becomes darker resulting uneven shades in printing.

Myrobalan is an important tannin-based mordant for cellulosic fiber, namely, cotton. Treatment with tannin introduces additional hydroxyl and carboxyl groups on the fiber matrix. A subsequent treatment of tannin treated cellulose with metal salts introduces the respective cation in the fiber that leads to the formation of metal complexes.

\subsubsection{Preparation of Thickening Agents}

(1) Guar Gum. The guar gum powder was sprinkled slowly in lukewarm water with continuous stirring in order to prevent lump formation. The mixture was cooked for half an hour and allowed to be cooled.

(2) Albumin. Albumin was dissolved in cold water and kept for overnight to dissolve properly. For most purposes one part of albumin is mixed with one part of gum.

2.2.4. Preparation of Stock Paste. Mordants were first dissolved in water and then added to cold thickening agents (see Table 1). 
TABle 2: Printed sample coding.

\begin{tabular}{|c|c|c|c|c|}
\hline Fabric & Sample code & Mordant + thickener & Sample code & Mordant + thickener \\
\hline \multirow{4}{*}{ Untreated jute/cotton } & UJC1 & No mordant + guar gum & $\mathrm{UJCl}^{\prime}$ & No mordant + albumin \\
\hline & UJC2 & Alum + guar gum & $\mathrm{UJC}^{\prime}$ & Alum + albumin \\
\hline & UJC3 & $\mathrm{CuSO}_{4}+$ guar gum & $\mathrm{UJC}^{\prime}$ & $\mathrm{CuSO}_{4}+$ albumin \\
\hline & UJC4 & $\mathrm{FeSO}_{4}+$ guar gum & $\mathrm{UJC}^{\prime}$ & $\mathrm{FeSO}_{4}+$ albumin \\
\hline \multirow{3}{*}{ Myrobalan treated jute/cotton } & $\mathrm{MJC1}$ & Alum + guar gum & $\mathrm{MJCl}^{\prime}$ & Alum + albumin \\
\hline & MJC2 & $\mathrm{CuSO}_{4}+$ guar gum & $\mathrm{MJC}^{\prime}$ & $\mathrm{CuSO}_{4}+$ albumin \\
\hline & MJC3 & $\mathrm{FeSO}_{4}+$ guar gum & $\mathrm{MJC}^{\prime}$ & $\mathrm{FeSO}_{4}+$ albumin \\
\hline \multirow{4}{*}{ Untreated jute/wool } & UJW1 & No mordant + guar gum & UJW1' $^{\prime}$ & No mordant + albumin \\
\hline & UJW2 & Alum + guar gum & UJW2' & Alum + albumin \\
\hline & UJW3 & $\mathrm{CuSO}_{4}+$ guar gum & UJW3' & $\mathrm{CuSO}_{4}+$ albumin \\
\hline & UJW4 & $\mathrm{FeSO}_{4}+$ guar gum & UJW $4^{\prime}$ & $\mathrm{FeSO}_{4}+$ albumin \\
\hline \multirow{3}{*}{ Myrobalan treated jute/wool } & MJW1 & Alum + guar gum & MJW1' & Alum + albumin \\
\hline & MJW2 & $\mathrm{CuSO}_{4}+$ guar gum & MJW2' & $\mathrm{CuSO}_{4}+$ albumin \\
\hline & MJW3 & $\mathrm{FeSO}_{4}+$ guar gum & MJW3' & $\mathrm{FeSO}_{4}+$ albumin \\
\hline
\end{tabular}

\subsubsection{Print Paste}

(1) Jute/Cotton Union Fabric. The printing pastes for jute/cotton union fabric were prepared using the following recipe:

Rheum emodi dye powder: $10 \mathrm{gm}$,

glycerin: $2.5 \mathrm{gm}$,

stock paste: $87.5 \mathrm{gm}$,

total weight of the paste: $100 \mathrm{gm}$.

(2) Jute/Wool Union Fabric. The printing pastes for jute/wool union fabric were prepared using the following recipe:

Rheum emodi dye powder: $10 \mathrm{gm}$;

glycerin: $2.5 \mathrm{gm}$;

acetic acid: $5 \mathrm{gm}$;

stock paste: $82.5 \mathrm{gm}$;

total weight of the paste: $100 \mathrm{gm}$. stirrer

The print paste was continuously stirred by a mechanical

2.2.6. Printing Procedure. Printing was carried out on both tannin pretreated fabrics and untreated fabrics using the flat screen technique. Printed samples were then dried. The samples were steamed in a saturated atmosphere for 30 minutes in a star steamer. Printed samples were washed with water and then dried in air (see Table 2).

2.3. Measurement of Color Strength. The printed samples were evaluated for the depth of the prints by light reflectance measurements using a JAYPAK 4802 colour matching system at D65 illuminate/10 Deg Observer. The color strength $(K / S$ value) was assessed using the Kubelka-Munk equation:

$$
\frac{K}{S}=\frac{(1-R)^{2}}{2 R},
$$

where $R$ is the reflectance at specific wavelengths, $K$ is the absorption coefficient, and $S$ is the scattering coefficient.

In general, higher the $K / S$ values the higher the depth of the colour on the fabric.

The colour of printed fabric samples was also measured in terms of CIELAB colour space, namely, color parameters $L^{*}$ (+ lightness; - darkness), $a^{*}$ (+ red; - green), and $b^{*}$ (+ yellow; - blue), by using Computer Colour Matching System [9, 10]. The total colour deference $\Delta E^{*}$ was also evaluated using the following equation:

$$
\Delta E_{a b}^{*}=\left[\left(\Delta L^{*}\right)^{2}+\left(\Delta a^{*}\right)^{2}+\left(\Delta b^{*}\right)^{2}\right]^{1 / 2},
$$

where

$$
\begin{gathered}
L^{*}=116\left(\frac{Y}{Y_{n}}\right)^{1 / 3}-16, \\
a^{*}=500\left[\left(\frac{X}{X_{n}}\right)^{1 / 3}-\left(\frac{Y}{Y_{n}}\right)^{1 / 3}\right], \\
b^{*}=200\left[\left(\frac{Y}{Y_{n}}\right)^{1 / 3}-\left(\frac{Z}{Z_{n}}\right)^{1 / 3}\right] .
\end{gathered}
$$

2.4. Tests for Fastness Properties. The fastness properties of the printed samples towards washing, rubbing, and light were assessed using standard methods.

Evaluation of color fastness to washing was determined as per IS: 764-1984 method using a Sasmira launder-O-meter and following IS-3 wash fastness method. The wash fastness rating was assessed using grey scale as per ISO-05-A02 (loss of shade depth) and ISO-105-AO3 (extent of staining). Colour fastness to rubbing (dry and wet) was assessed as per IS: 7661984 method using a manually operated Paramount crock meter. Colour fastness to light was determined as per IS: 2454-1984 method. The sample was exposed to xenon light in a Paramount digiLIGHT fade-O-meter along with the eight blue wool standards (BS 1006: BOI: 1978). The fading 
TABLE 3: Yielding of colours with different mordants.

\begin{tabular}{lc}
\hline Sample code & Color obtained \\
\hline UJC1 & Yellow ochre \\
UJC2 & Light brown \\
UJC3 & Brown \\
UJC4 & Gray (light grayish ash) \\
MJC1 & Brown (cinnamon-copper shade) \\
MJC2 & Brown (dark cinnamon shade) \\
MJC3 & Gray-black \\
UJW1 & Yellowish brown \\
UJW2 & Deep brown \\
UJW3 & Deep brown (russet) \\
UJW4 & Gray \\
MJW1 & Brownish yellow \\
MJW2 & Deep brown (russet) \\
MJW3 & Deep brown \\
UJC1 $^{\prime}$ & Earth yellow \\
UJC2 $^{\prime}$ & Deep brown \\
UJC3 $^{\prime}$ & Deep brown (brown-nose) \\
UJC4 $^{\prime}$ & Deep brown (seal brown) \\
MJC1' $^{\prime}$ & Golden-brown \\
MJC2 $^{\prime}$ & Brown \\
MJC3 $^{\prime}$ & Yellowish brown \\
UJW1 $^{\prime}$ & Yellowish brown \\
UJW2 $^{\prime}$ & Dark goldenrod \\
UJW3 $^{\prime}$ & Dark goldenrod \\
UJW4 $^{\prime}$ & Coffee brown \\
MJW1 & Grownish yellow \\
MJW2 & Olive black \\
MJW3 & \\
\hline &
\end{tabular}

of each sample was observed against the fading of blue wool standards (1-8).

\section{Results and Discussion}

The $K / S$ value (Figures 2 and 3 ) indicates that mordants, namely, $\mathrm{CuSO}_{4}$ and $\mathrm{FeSO}_{4}$ exhibited high colour absorption $(K / S)$ regardless of the nature of material used, which may be attributed to their ability to form strong coordination complexes with the dye molecules. Furthermore, the high colour absorption and colour difference (Tables 3 and 4) to a certain extent may be due to the changes in scattering because of the chemical interactions between fibers and tannin and/or metallic salts along with the additional inherent colour input of the corresponding mordants.

Jute-wool union printed fabrics pretreated with myrobalan showed comparatively higher $K / S$ values than the untreated fabrics; furthermore, the $K / S$ values in case of jute-wool union fabrics were in most cases higher than their corresponding samples of jute-cotton union fabrics exception being jute-cotton untreated fabric particularly UJC2 ${ }^{\prime}$ and UJC3' printed using albumin as thickening agent which yielded darker and shining shades. This may be due to

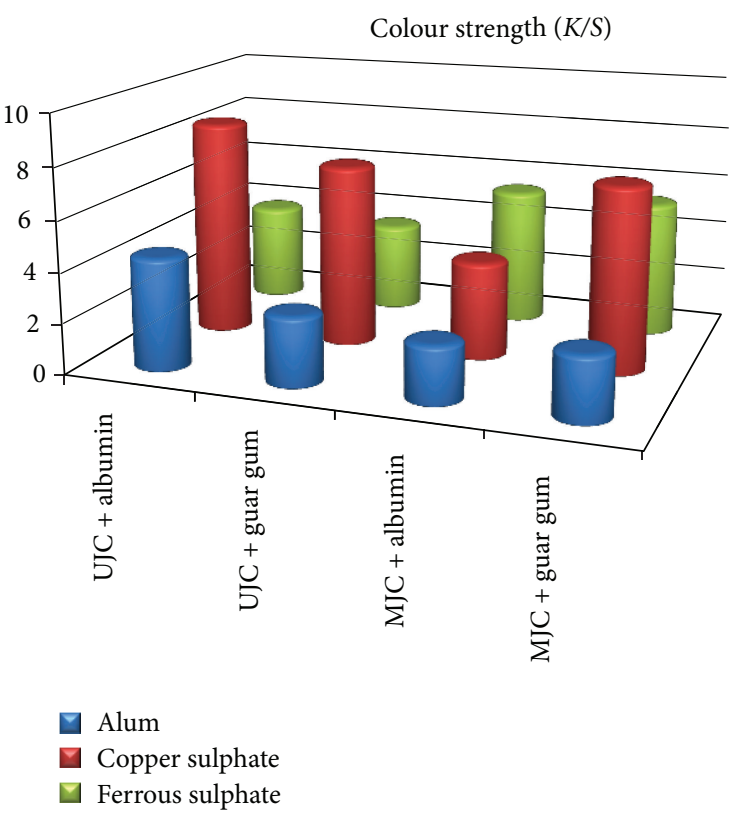

FigURE 2: Effect of mordants and thickeners on color strength of jute/cotton union fabrics.

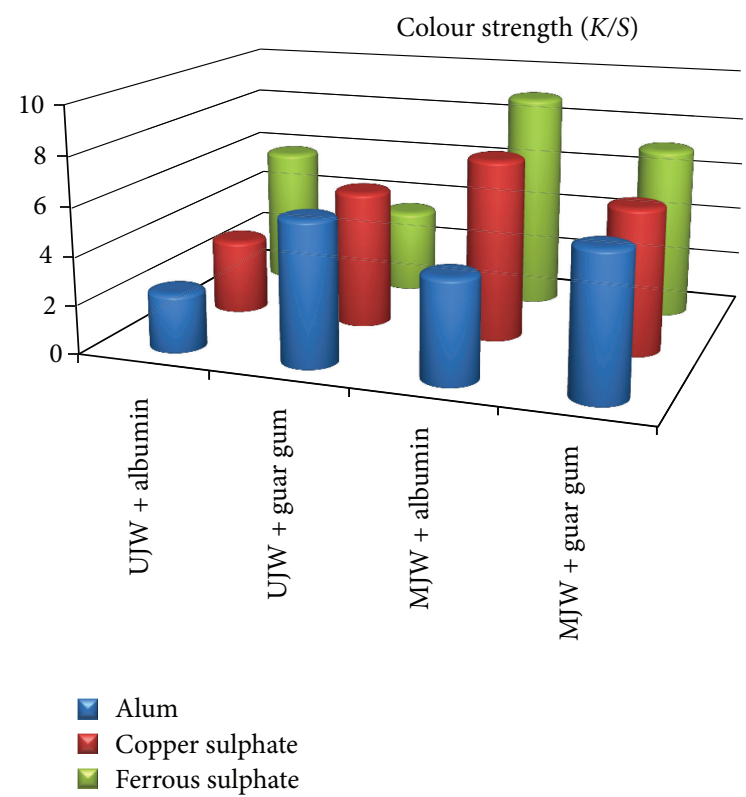

FIGURE 3: Effect of mordants and thickeners on color strength of jute/wool union fabrics.

the fact that myrobalan contains natural colour as well as natural tannin and in addition to that in case of protein fiber such as wool, three types of bonds, namely, hydrogen bond, ionic bond, and covalent bond, are formed. However, in case of cellulosic fabrics the tannin could form only two types of bonds, that is, hydrogen bond and covalent bond. Moreover, the penetration of mordant and colour in wool is easier than that of cellulose fibers, as the fiber is porous, softer, and more elastic; hence higher colour absorption occurs in case 
TABLE 4: CIELAB lab measurements.

\begin{tabular}{|c|c|c|c|c|c|}
\hline \multirow{2}{*}{ Sample code } & \multirow{2}{*}{ Mordant + thickener } & \multicolumn{4}{|c|}{ Delta CIELAB } \\
\hline & & $\Delta E^{*}$ & $\Delta L^{*}$ & $\Delta a^{*}$ & $\Delta b^{*}$ \\
\hline UJC1 & No mordant + guar gum & - & - & - & - \\
\hline UJC2 & Alum + guar gum & 8.36 & 7.45 & -2.30 & -3.03 \\
\hline UJC3 & $\mathrm{CuSO}_{4}+$ guar gum & 25.13 & -23.98 & 7.17 & -2.36 \\
\hline UJC4 & $\mathrm{FeSO}_{4}+$ guar gum & 12.91 & -7.06 & 1.63 & -10.69 \\
\hline $\mathrm{UJCl}^{\prime}$ & No mordant + albumin & 8.42 & -2.21 & 0.50 & 8.11 \\
\hline UJC2' & Alum + albumin & 15.40 & -10.18 & 0.53 & 11.55 \\
\hline UJC3' & $\mathrm{CuSO}_{4}+$ albumin & 29.15 & -28.32 & 6.76 & -1.59 \\
\hline UJC4 ${ }^{\prime}$ & $\mathrm{FeSO}_{4}+$ albumin & 14.05 & -13.95 & 1.15 & -1.29 \\
\hline MJC1 & Alum + guar gum & 6.12 & 4.24 & 0.46 & -4.39 \\
\hline MJC2 & $\mathrm{CuSO}_{4}+$ guar gum & 25.85 & -24.31 & 7.21 & 5.12 \\
\hline MJC3 & $\mathrm{FeSO}_{4}+$ guar gum & 20.64 & -20.23 & -0.11 & 4.11 \\
\hline $\mathrm{MJC1}^{\prime}$ & Alum + albumin & 2.98 & -2.82 & 0.99 & 0.04 \\
\hline MJC2' & $\mathrm{CuSO}_{4}+$ albumin & 13.17 & -11.47 & 1.36 & 6.34 \\
\hline $\mathrm{MJC3}^{\prime}$ & $\mathrm{FeSO}_{4}+$ albumin & 20.67 & -20.43 & 1.35 & -2.86 \\
\hline UJW1 & No mordant + guar gum & 7.66 & -2.95 & 5.72 & 4.16 \\
\hline UJW2 & Alum + guar gum & 22.89 & -22.24 & 3.56 & 4.11 \\
\hline UJW3 & $\mathrm{CuSO}_{4}+$ guar gum & 20.81 & -19.81 & 6.18 & -1.59 \\
\hline UJW4 & $\mathrm{FeSO}_{4}+$ guar gum & 10.26 & -10.15 & 1.02 & -1.17 \\
\hline UJW1' & No mordant + albumin & 11.01 & 0.25 & -0.37 & 11.01 \\
\hline UJW2' & Alum + albumin & 3.60 & 3.48 & -0.82 & 0.4 \\
\hline UJW3' & $\mathrm{CuSO}_{4}+$ albumin & 9.19 & -6.40 & -0.01 & -6.60 \\
\hline UJW $4^{\prime}$ & $\mathrm{FeSO}_{4}+$ albumin & 22.39 & -20.95 & 6.72 & -4.16 \\
\hline MJW1 & Alum + guar gum & 23.38 & -22.46 & 2.27 & 6.11 \\
\hline MJW2 & $\mathrm{CuSO}_{4}+$ guar gum & 22.87 & -22.30 & 0.12 & 5.11 \\
\hline MJW3 & $\mathrm{FeSO}_{4}+$ guar gum & 25.08 & -23.75 & 8.02 & -0.94 \\
\hline $\mathrm{MJW1}^{\prime}$ & Alum + albumin & 15.04 & -14.95 & 1.22 & -1.14 \\
\hline MJW2' & $\mathrm{CuSO}_{4}+$ albumin & 26.18 & -25.61 & 2.71 & 4.75 \\
\hline MJW3' & $\mathrm{FeSO}_{4}+$ albumin & 30.25 & -29.02 & 7.76 & -3.59 \\
\hline
\end{tabular}

TABLE 5: Fastness properties of the printed jute/cotton union fabrics towards washing, rubbing, and light.

\begin{tabular}{|c|c|c|c|c|c|c|c|}
\hline \multirow{3}{*}{ Sample code } & \multirow{3}{*}{ Mordant + thickener } & \multicolumn{3}{|c|}{ Washing fastness } & \multicolumn{2}{|c|}{ Rubbing fastness } & \multirow{3}{*}{ Light fastness } \\
\hline & & \multirow{2}{*}{$\mathrm{CC}$} & \multicolumn{2}{|c|}{ CS } & \multirow{2}{*}{ Dry } & \multirow{2}{*}{ Wet } & \\
\hline & & & $\mathrm{C}$ & $\mathrm{W}$ & & & \\
\hline UJC1 & No mordant + guar gum & 3 & $3-4$ & 3 & $3-4$ & 3 & 4 \\
\hline UJC2 & Alum + guar gum & $4-5$ & 5 & $4-5$ & 5 & $4-5$ & 6 \\
\hline UJC3 & $\mathrm{CuSO}_{4}+$ guar gum & 5 & 5 & 5 & 5 & 5 & 7 \\
\hline UJC4 & $\mathrm{FeSO}_{4}+$ guar gum & 4 & 4 & $4-5$ & $4-5$ & 4 & 6 \\
\hline $\mathrm{UJCl}^{\prime}$ & No mordant + albumin & $4-5$ & $4-5$ & $4-5$ & $4-5$ & $4-5$ & 6 \\
\hline UJC2' & Alum + albumin & $4-5$ & $4-5$ & $4-5$ & 5 & $4-5$ & $6-7$ \\
\hline $\mathrm{UJC}^{\prime}$ & $\mathrm{CuSO}_{4}+$ albumin & 5 & 5 & 5 & 5 & 5 & 7 \\
\hline UJC4 ${ }^{\prime}$ & $\mathrm{FeSO}_{4}+$ albumin & 5 & 5 & $4-5$ & $4-5$ & $4-5$ & 7 \\
\hline MJC1 & Alum + guar gum & $4-5$ & $4-5$ & $4-5$ & 5 & $4-5$ & $6-7$ \\
\hline MJC2 & $\mathrm{CuSO}_{4}+$ guar gum & $4-5$ & 5 & $4-5$ & 5 & 5 & 7 \\
\hline MJC3 & $\mathrm{FeSO}_{4}+$ guar gum & $4-5$ & $4-5$ & $4-5$ & $4-5$ & $4-5$ & 6 \\
\hline $\mathrm{MJCl}^{\prime}$ & Alum + albumin & $4-5$ & $4-5$ & 5 & 5 & $4-5$ & $6-7$ \\
\hline MJC2' & $\mathrm{CuSO}_{4}+$ albumin & 5 & 5 & 5 & 5 & 5 & 7 \\
\hline $\mathrm{MJC}^{\prime}$ & $\mathrm{FeSO}_{4}+$ albumin & 5 & 5 & 5 & 5 & $4-5$ & 7 \\
\hline
\end{tabular}

CC: color change; CS: color staining; C: cotton; W: wool. 
TABLE 6: Fastness properties of the printed jute/wool union fabrics towards washing, rubbing, and light.

\begin{tabular}{|c|c|c|c|c|c|c|c|}
\hline \multirow{3}{*}{ Fabric } & \multirow{3}{*}{ Mordant + thickener } & \multicolumn{3}{|c|}{ Washing fastness } & \multicolumn{2}{|c|}{ Rubbing fastness } & \multirow{3}{*}{ Light fastness } \\
\hline & & \multirow{2}{*}{$\mathrm{CC}$} & \multicolumn{2}{|c|}{ CS } & \multirow{2}{*}{ Dry } & \multirow{2}{*}{ Wet } & \\
\hline & & & $\mathrm{C}$ & $\mathrm{W}$ & & & \\
\hline UJW1 & No mordant + guar gum & 3 & 4 & $3-4$ & $3-4$ & $3-4$ & 4 \\
\hline UJW2 & Alum + guar gum & $4-5$ & $4-5$ & $4-5$ & $4-5$ & 5 & $6-7$ \\
\hline UJW3 & $\mathrm{CuSO}_{4}+$ guar gum & 5 & 5 & 5 & 5 & 5 & $6-7$ \\
\hline UJW4 & $\mathrm{FeSO}_{4}+$ guar gum & 5 & $4-5$ & 5 & 5 & $4-5$ & 6 \\
\hline UJW1' & No mordant + albumin & $4-5$ & $4-5$ & $4-5$ & 5 & $4-5$ & $6-7$ \\
\hline UJW2' & Alum + albumin & 5 & 5 & $4-5$ & 5 & 5 & 7 \\
\hline UJW3' $^{\prime}$ & $\mathrm{CuSO}_{4}+$ albumin & 5 & 5 & 5 & 5 & 5 & 7 \\
\hline UJW4' & $\mathrm{FeSO}_{4}+$ albumin & 5 & $4-5$ & 5 & 5 & 5 & 7 \\
\hline MJW1 & Alum + guar gum & $4-5$ & $4-5$ & $4-5$ & $4-5$ & $4-5$ & $6-7$ \\
\hline MJW2 & $\mathrm{CuSO}_{4}+$ guar gum & $4-5$ & $4-5$ & 5 & 5 & 5 & $6-7$ \\
\hline MJW3 & $\mathrm{FeSO}_{4}+$ guar gum & 5 & $4-5$ & 5 & 5 & $4-5$ & $6-7$ \\
\hline $\mathrm{MJW1}^{\prime}$ & Alum + albumin & $4-5$ & 5 & $4-5$ & 5 & $4-5$ & 7 \\
\hline MJW2' & $\mathrm{CuSO}_{4}+$ albumin & 5 & 5 & $4-5$ & 5 & 5 & 7 \\
\hline MJW3' & $\mathrm{FeSO}_{4}+$ albumin & 5 & 5 & 5 & 5 & 5 & 7 \\
\hline
\end{tabular}

CC: color change; CS: color staining; C: cotton; W: wool.

of myrobalan treated jute-wool union printed fabrics. Regarding jute-cotton untreated fabric yielding darker shades with albumin as thickening agent, it may be due to the fact that albumin being a heat-coagulating protein acts as a mordant thus increasing the colour absorption for a number of colors, despite that guar gum as a thickening agent is also nearly as efficient as albumin. Furthermore, considering the cost, availability and ethical issue, guar gum is the best choice as guar is a native plant abundantly available, the most economical, and can be used for most types of printing owing to its stability in all $\mathrm{pH}$ levels and, therefore, suitable print-paste thickener unlike albumin.

Colour analysis in terms of lightness $\left(\Delta L^{*}\right)$ and the Cartesian coordinates $\Delta a^{*}$ and $\Delta b^{*}$ showed that the overall principal colours yielded on jute-cotton and jute-wool union fabrics were ranged from yellow ochre, yellowish brown, deep brown, grey, and coffee to olive black and affected by the type of mordant used. The addition of a mordant to an appropriate colorant results in sudden change in color owing to the incorporation of the metal atom which has low energy levels, into the delocalized electron system of the dye, subsequently lowering of the overall energy. The absorbance of the hue and thus its color is related to this phenomenon.

On the $L^{*}$ plane, the measurement difference of values was positive in case of a few samples printed with alum mordant (UJC2, MJC1, UJW1', and UJW2' ${ }^{\prime}$ ) corresponding to lighter shades, whereas the $\Delta L^{*}$ values were found to be negative in case of all other samples mordanted with alum, copper sulphate, and ferrous sulphate corresponding to darker shades. It is evident that the type of shades produced and the level of absorption of colorant were affected by using the different mordants and pretreatment with myrobalan whose chemical reaction with the natural colorant depended on the unique structures of the colour components and on the strength of the tannin and/or metal-colorant coordination complex formed during the printing process.
Tables 5 and 6 revealed the fastness properties of the printed samples. Both untreated and myrobalan treated jute union fabrics printed with copper sulphate and ferrous sulphate mordants showed excellent colorfastness properties. Furthermore, the overall fastness properties such as washing, rubbing and light for all mordanted samples were very satisfactory (rating lies between good to excellent) regardless of the nature of materials, mordants, and thickeners used. Thus, it is evident that the complex mixture of anthraquinone structures of Rheum emodi is capable of forming stable complexes with the metal ions, resulting in improved colourfastness to washing, rubbing, and lightfastness. Besides, presence of anthraquinone structure as is found in Rheum emodi shows in general an increased resistance to light fading [11]. Moreover, albumin being a heat-coagulating protein acts as fixing agent and, hence, further enhances the fastness properties of jute union fabrics.

\section{Conclusions}

(i) The choice of mordants, thickeners, and fibers types has significant influence on colour values. Printing with Rheum emodi (Himalayan rhubarb) colorant with different mordants resulted in different shades ranging from yellowish brown, deep brown, reddish brown, and gray shades to olive black. The $K / S$ value showed that mordants, namely, $\mathrm{CuSO}_{4}$ and $\mathrm{FeSO}_{4}$ exhibited high colour absorption $(K / S)$ regardless of the nature of material used.

(ii) All the printed samples have good to excellent wash, rubbing, and light fastness properties regardless of the nature of materials, mordants, and thickeners used. Both untreated and myrobalan treated jute/cotton fabrics printed with copper sulphate and ferrous 
sulphate mordants showed excellent all round colorfastness properties.

(iii) Guar gum is closely at par with albumin as a thickening agent and considering the cost, availability, and ethical issue, guar gum is the best choice as guar is a native plant abundantly available and cheap unlike albumin.

It can be concluded from the present investigation that the natural colorant Rheum emodi can be successfully employed to print jute-cotton and jute-wool union fabrics.

\section{Conflict of Interests}

The author declares that there is no conflict of interests regarding the publication of this paper.

\section{Acknowledgment}

The author expresses Sincere thanks to Ms. Ankita Saxena for her encourage and help to complete this minor project.

\section{References}

[1] S. P. Mishra, Text Book of Fiber Science and Technology, Newage International, 2005.

[2] B. N. Bandyopadhyay and N. R. Salaskar, "Prospects of jute," Indian Textile Journal, vol. 12, no. 5, pp. 12-25, 1997.

[3] T. Bechtold and R. Mussak, Eds., Natural Colorants-Quinoid, Naphthoquinoid and Anthraquinoid Dyes, John Wiley and Sons, 2009.

[4] M. S. Akhtar, M. Amin, M. Ahmad, and Alamgeer, "Hepatoprotective effect of Rheum emodi roots (Revand chini) and Akseere-Jigar against paracetamol-induced hepatotoxicity in rats," Ethnobotanical Leaflets, vol. 13, pp. 310-315, 2009.

[5] D. Das, S. R. Maulik, and S. C. Bhattacharya, "Colouration of wool and silk with Rheum emodi," Indian Journal of Fibre and Textile Research, vol. 33, no. 2, pp. 163-170, 2008.

[6] A. K. Samanta and A. Konar, "Dyeing of Textiles with Natural Dyes," in Natural Dyes, P. A. Kumbasar, Ed., pp. 30-56, InTech, 2011.

[7] M. Dressler, P. Fischer, and E. J. Windhab, "Rheological characterization and modeling of aqueous guar gum solutions," in Proceedings of the 3rd International Symposium on Food Rheology and Structure, pp. 249-253, 2002.

[8] "The Columbia Electronic Encyclopedia," Columbia University Press, 2013, http://cup.columbia.edu/.

[9] "Applications Notes: insight on Color, CIE L*a* b* Color Scale," HunterLab, vol. 8, no. 7, pp. 1-4, 2008.

[10] P. B. Tayade and R. V. Adivarekar, "Dyeing of silk fabric with Cuminum Cyminum $\mathrm{L}$ as a source of natural dye," International Journal of ChemTech Research, vol. 5, no. 2, pp. 699-706, 2013.

[11] N. S. Allen, "Photofading mechanisms of dyes in solution and polymer media," Review of Progress in Coloration and Related Topics, vol. 17, no. 1, pp. 61-71, 1987. 

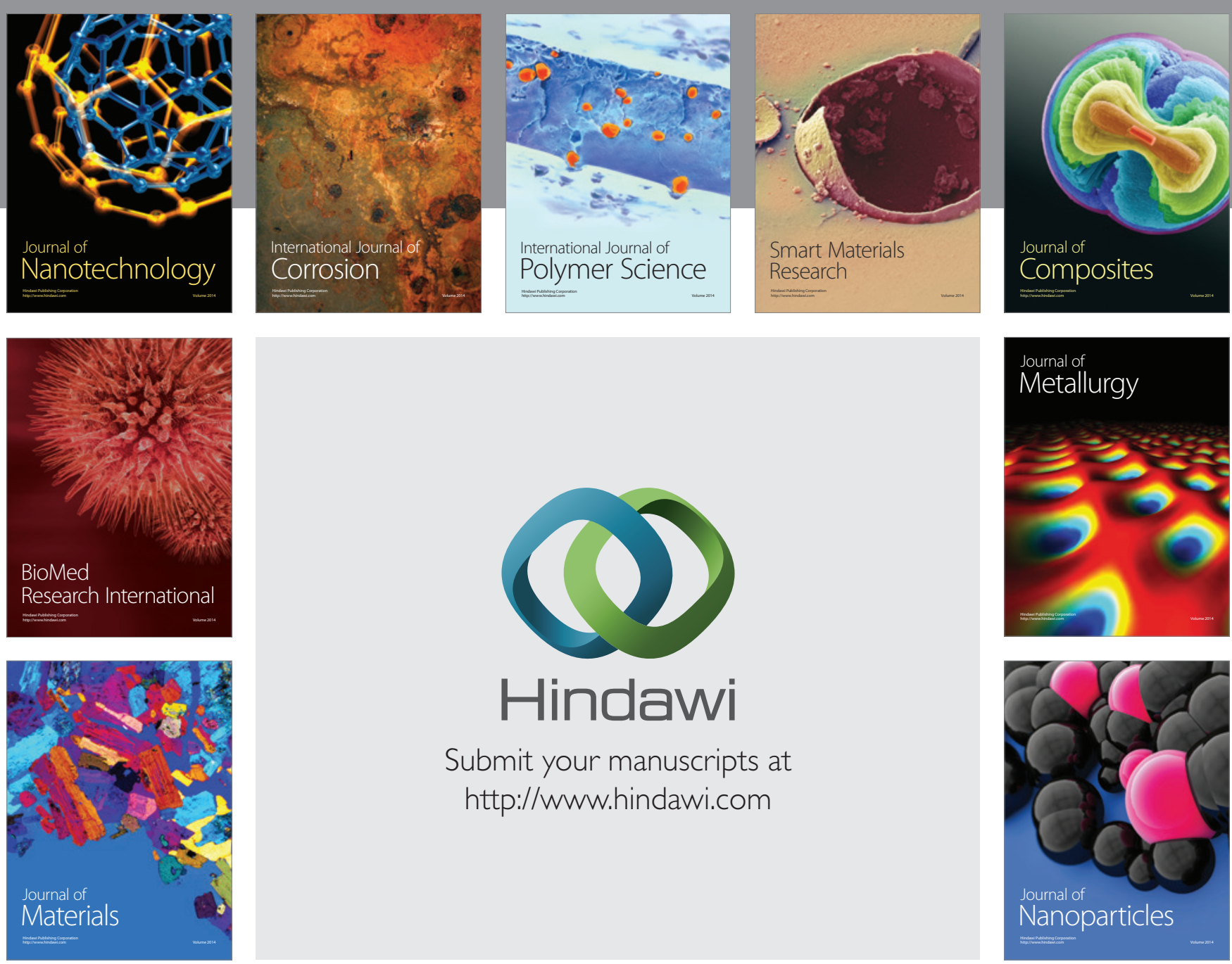

Submit your manuscripts at http://www.hindawi.com
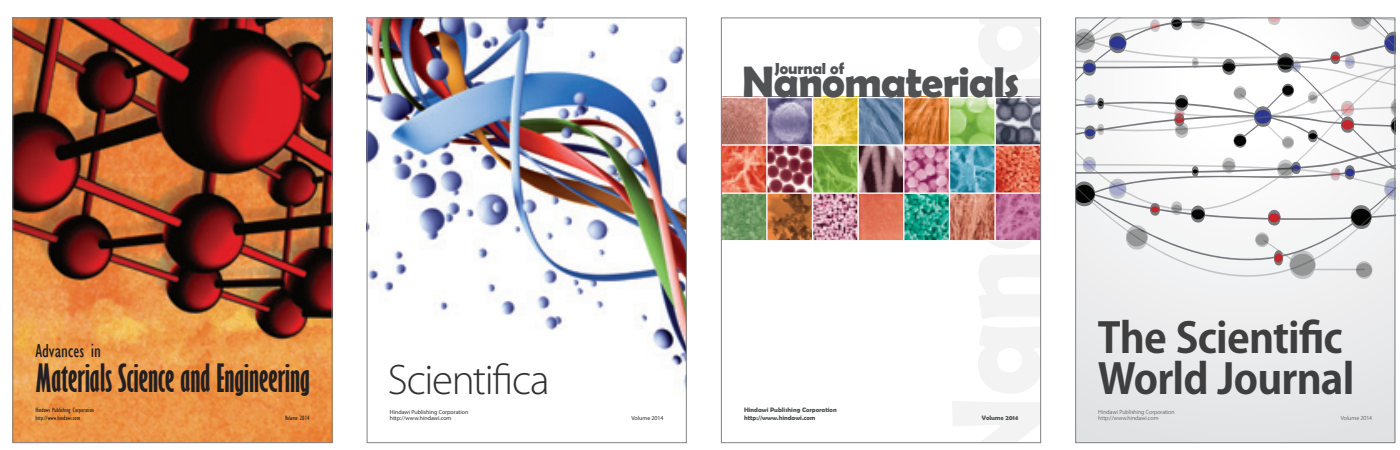

\section{The Scientific World Journal}
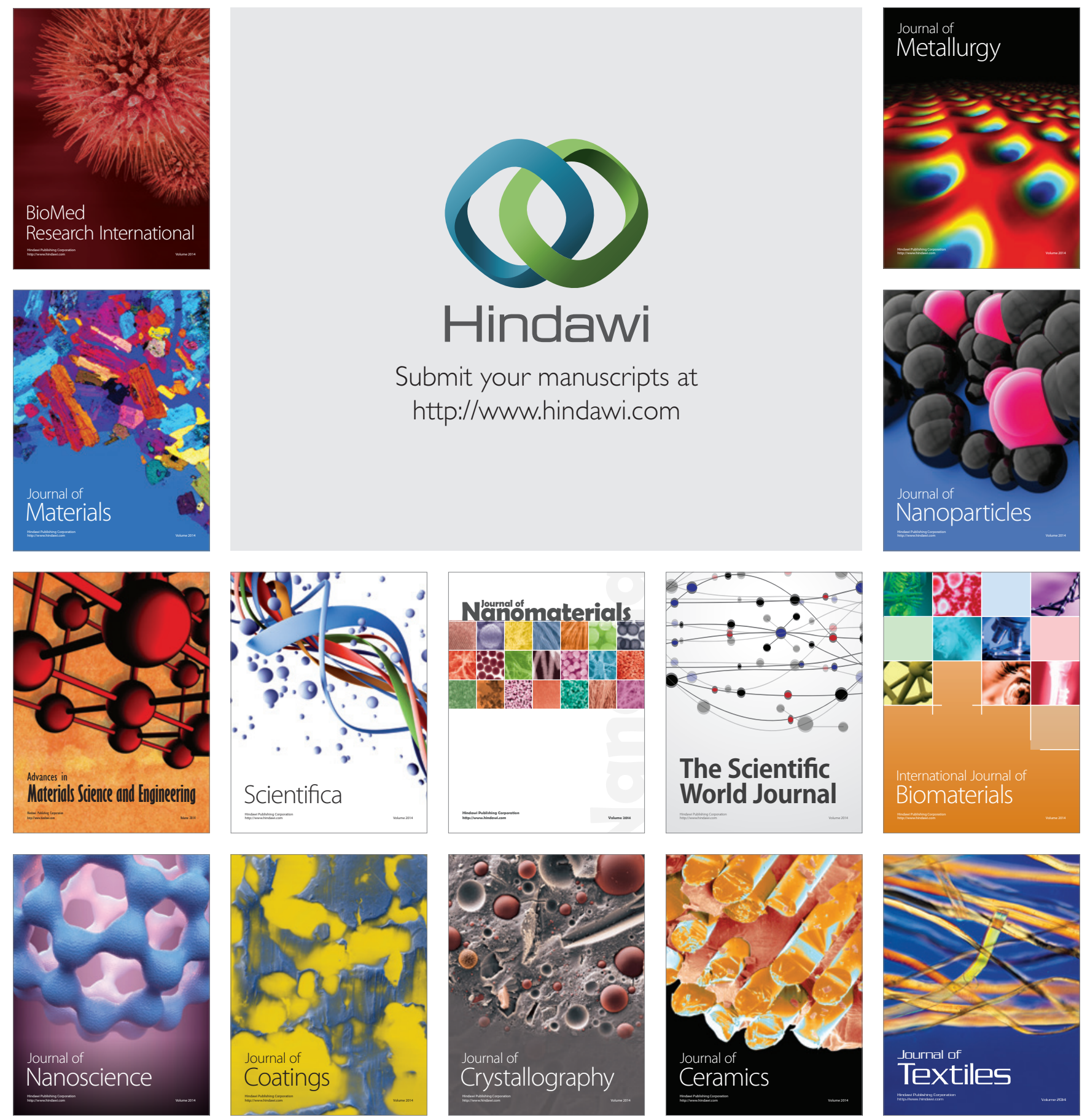